University of Nebraska - Lincoln

DigitalCommons@University of Nebraska - Lincoln

Uniformed Services University of the Health

Sciences

U.S. Department of Defense

2001

Predictors of patient satisfaction

Jeffrey L. Jackson

Uniformed Services University of the Health Sciences

Judith Chamberlin

Uniformed Services University of the Health Sciences

Kurt Kroenke

Indianapolis University School of Medicine

Follow this and additional works at: https://digitalcommons.unl.edu/usuhs

Part of the Medicine and Health Sciences Commons

Jackson, Jeffrey L.; Chamberlin, Judith; and Kroenke, Kurt, "Predictors of patient satisfaction" (2001). Uniformed Services University of the Health Sciences. 12.

https://digitalcommons.unl.edu/usuhs/12

This Article is brought to you for free and open access by the U.S. Department of Defense at DigitalCommons@University of Nebraska - Lincoln. It has been accepted for inclusion in Uniformed Services University of the Health Sciences by an authorized administrator of DigitalCommons@University of Nebraska Lincoln. 


\title{
Predictors of patient satisfaction ${ }^{\text {ts }}$
}

\author{
Jeffrey L. Jackson*,a,b Judith Chamberlin ${ }^{\mathrm{c}}$, Kurt Kroenke ${ }^{\mathrm{d}}$ \\ ${ }^{a}$ Department of Medicine, Uniformed Services University of the Health Sciences, 4301 Jones Bridge Road, Bethesda, MD 20814, USA \\ ${ }^{\mathrm{b}}$ Walter Reed Army Medical Center, Washington, DC, USA \\ ${ }^{\mathrm{c}}$ Department of Preventive Medicine and Biometrics, Uniformed Services University of the Health Sciences, Bethesda, MD, USA \\ ${ }^{\mathrm{d}}$ Department of Medicine, Regenstrief Institute for Health Care, Indianapolis University School of Medicine, Indianapolis, IN, USA
}

\begin{abstract}
Correlates of patient satisfaction at varying points in time were assessed using a survey with 2-week and 3-month follow-up in a general medicine walk-in clinic, in USA. Five hundred adults presenting with a physical symptom, seen by one of 38 participating clinicians were surveyed and the following measurements were taken into account: patient symptom characteristics, symptom-related expectations, functional status (Medical Outcomes Study Short-Form Health Survey [SF-6]), mental disorders (PRIME-MD), symptom resolution, unmet expectations, satisfaction (RAND 9-item survey), visit costs and health utilization. Physician perception of difficulty (Difficult Doctor-Patient Relationship Questionnaire), and Physician Belief Scale. Immediately after the visit, 260 (52\%) patients were fully satisfied with their care, increasing to $59 \%$ at 2 weeks and $63 \%$ by 3 months. Patients older than 65 and those with better functional status were more likely to be satisfied. At all time points, the presence of unmet expectations markedly decreased satisfaction: immediately post-visit (OR: 0.14, 95\% CI: 0.07-0.30), 2-week (OR: 0.07, 95\% CI: 0.04-0.13) and 3-month (OR: 0.05, 95\% CI: 0.03-0.09). Other independent variables predicting immediate after visit satisfaction included receiving an explanation of the likely cause as well as expected duration of the presenting symptom. At 2 weeks and 3 months, experiencing symptomatic improvement increased satisfaction while additional visits (actual or anticipated) for the same symptom decreased satisfaction. A lack of unmet expectations was a powerful predictor of satisfaction at all time-points. Immediately post-visit, other predictors of satisfaction reflected aspects of patient-doctor communication (receiving an explanation of the symptom cause, likely duration, lack of unmet expectations), while 2week and 3-month satisfaction reflected aspects of symptom outcome (symptom resolution, need for repeat visits, functional status). Patient satisfaction surveys need to carefully consider the sampling time frame as well as adjust for pertinent patient characteristics. (C) 2001 Elsevier Science Ltd. All rights reserved.
\end{abstract}

Keywords: Patient-doctor relationship; Satisfaction; USA

\section{Introduction}

Patient satisfaction has emerged as an increasingly important health outcome and is currently used for four related but distinct purposes (Locker \& Dunt, 1978): (1)

\footnotetext{
${ }^{3}$ The views expressed in this article are those of the authors and should not be construed to represent in any way those of the Department of Defense or the Department of the Army.

*Corresponding author. Tel.: +1-202-782-4039; fax: + 1202-782-7363.

E-mail address: jejackson@usuhs.mil (J.L. Jackson).
}

to compare different health care programs or systems; (2) to evaluate the quality of care (Rubin, Gandek, Rogers, Kosinski, McHorney \& Ware, 1993); (3) to identify which aspects of a service need to be changed to improve patient satisfaction (Jackson \& Kroenke, 1997); and (4) to assist organizations in identifying consumers likely to disenroll (Weiss \& Senf, 1990). Satisfaction is believed to be an attitudinal response to value judgments that patients make about their clinical encounter (Kane, Maciejewski \& Finch, 1997). Despite the increased focus on satisfaction as an outcome measure and a growing body of research, satisfaction has remained difficult to 
compartmentalize. While numerous satisfaction surveys have been developed, most with acceptable psychometric properties, the factors individual patients use to deem themselves satisfied remains largely unknown. Consequently, studies measuring predictors of satisfaction have explained only a small portion of satisfaction's variance, nearly always less than $20 \%$. (Jackson \& Kroenke, 1997)

Jones, Carnon, Wylie and Hedley (1993) administered a 300-question survey covering a range of satisfaction variables within and outside the provider's control to 1357 patients, and concluded "other important considerations from the set of unmeasured attributes must provide the bulk of the explanation." Linder-Pelz (1982a, 1982b) argued that the low power to explain satisfaction is due to lack of good models of satisfaction, with most studies relying on post-hoc correlational analysis rather than model driven research. She generated and tested five hypotheses regarding social and psychological determinants of patient satisfaction. Although she found that patient expectations, values and perceived occurrences all had independent effects on patient satisfaction, these variables explained less than $10 \%$ of total variance (Linder-Pelz, 1982a, 1982b). Kane et al. (1997) in a study of patients 6 months after undergoing cholecystectomy proposed two models for satisfaction:

- Model $1-$ Satisfaction $=$ Outcomes + Severity + Demographics + Procedure;

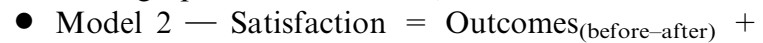
Severity $_{(\text {before-after }}+$ Demographics + Procedure.

The difference in these two models is that the first one is based on absolute patient outcomes, while the second on incremental improvement in symptoms during the follow-up period. While both models had some predictive power, absolute levels of patient health were more predictive than relative changes in functioning (Kane et al., 1997). Unfortunately, only $8 \%$ of satisfaction was explained with either of these models.

Some studies have focused on physician communication skills and have found a relationship with satisfaction. In particular, specific communication barriers, including lack of warmth and friendliness on the part of the doctor, failure to take into account the patient's concerns and expectations, lack of a clear cut explanation concerning diagnosis and causation of illness, and excessive use of medical jargon have been found to decrease satisfaction (Korsch, Gozzi \& Francis, 1968; Roter, Stewart, Putnam, Lipkin, Stiles \& Inui, 1997). However, physician characteristics have consistently contributed only a small portion of variance.

Other researchers have explored the possible influence of patient demographics and health status. While older patients are generally more satisfied than younger patients (Williams, 1994; Larsen \& Rootman, 1976; Henley \& Davis, 1967; Hall \& Dornan, 1990), other demographic characteristics, such as sex and race seem to be unimportant (Zastowny, Roghman \& Hengst, 1983; Marple, Lucey, Kroenke, Wilder \& Lucas, 1997). Baseline health status also appears to play a role since patients reporting their health as poor are less satisfied than those who describe themselves as healthy (Cleary \& McNeil, 1988; Cleary et al., 1991; Williams \& Calnan, 1991; Temkin-Greener \& Winchell, 1991; Covinsky et al., 1988; Hermann, Ettner \& Dorwart, 1998). However, health status appears to exert only a small independent effect on satisfaction when adjustment for other variables is made (Linder-Pelz, 1982a, 1982b; Marple et al., 1997).

Satisfaction may also be influenced by the patient's mental state. Psychological distress (Greenley, Young \& Schoenherr, 1982), depression (Linn \& Greenfield, 1982; Hansson, Borgquist, Nettelbladt \& Nordstrom, 1994; Wyashak \& Barsky, 1995) and personality disorders (Hueston, Mainous \& Schilling, 1996) have been associated with lower levels of satisfaction. Lower satisfaction has also been found among elderly, disabled medicare beneficiaries (Hermann et al., 1998).

Unmet patient expectations may also affect satisfaction. While most patients have specific expectations for their health care visit (Kravitz, Cope, Bhrany \& Leake, 1994; Good, Good \& Nassi, 1983; Uhlmann, Carter \& Inui, 1984a; Uhlmann, Inui \& Carter, 1984b; Greene, Weinberger \& Mamlin, 1980; Sanchez-Menegay \& Stalder, 1994; Burgoyne, Staples, Yamamoto, Wolkon \& Kline, 1979; Lazare \& Eisenthal, 1977; Kravitz, Callahan, Paterniti, Antoneius, Dunham \& Lewis, 1996), physicians are frequently unaware of these desires and consequently fail to recognize or address expectations $18-42 \%$ of the time. Preliminary evidence suggests that a lack of unmet expectations is associated with greater satisfaction (Marple et al., 1997) and even improved outcome (Brody, Miller, Lerman, Smith, Lazaro \& Blum, 1989). One study found that unmet expectations accounted for $19 \%$ of the variance in patient satisfaction with the encounter (Like \& Zyzanski, 1987).

Jatulis, Bundek and Legorreta (1997) found that patients rated health outcomes of care as the most important variable in deeming themselves satisfied. This survey asked patients to rate factors important in determining satisfaction, and purports to explain over $80 \%$ of satisfaction's variance. However, this study measured variables patients 'in theory' would use in judging satisfaction. No satisfaction levels or outcomes of care were actually measured.

We previously conducted a clinical, pre-post trial in which we provided physicians pre-visit information on patients' expectations and mental disorders to the second half of a 500 patient cohort. While we reduced 
unmet expectations, there was no change in patient satisfaction or other symptom-related outcomes (Jackson, Kroenke \& Chamberlin, 1999a). From this cohort of 500 patients, we sought to explore, in a groundedtheory approach: (1) what patient or physician characteristics independently correlate with patient satisfaction? (2) what is the relative contribution of the many satisfaction variables identified in previous studies? and, (3) are these correlates constant over time?

\section{Methods}

Adults presenting to the general medicine walk-in clinic at Walter Reed Army Medical Center with a chief complaint of a physical symptom were eligible to participate. Exclusion criteria included dementia or an upper respiratory infection (URI) as the primary symptom, since one aim of this study was to assess 3month outcomes and $90 \%$ of URIs resolve within 2 weeks. This clinic primarily provides continuity of care appointments, but has walk-in appointments available for patients desiring to be seen that day. Such walk-in patients are assigned to physicians on a queue system: first come, first assigned to the next available clinician. The clinician is assigned from a roster of available appointments, with clinicians listed alphabetically within each time slot. Physicians seeing them for the first time saw most study patients. The demographics, medical and psychiatric comorbidity, and satisfaction with care of patients seen in the general medicine clinic of a military teaching hospital are comparable to civilian settings (Jackson et al., 1999a; Jackson, Strong, Cheng \& Meyer, 1999b; Jackson, Cheng, Jones \& Meyer, 1999; Johnson, Pinhott, Jenkins \& Carpenter, 1988). Our institutions' human use committee approved this protocol.

\section{Patient variables}

\section{Pre-visit surveys}

Immediately before seeing the physician, all patients completed a questionnaire on symptom severity (0-10 scale) and duration (days); previous visits for the symptom (yes/no); worry about serious illness (yes/no); stress in the previous week (yes/no); and presence of common symptom-related expectations (causal explanation, expected duration, prescription, diagnostic test, referral, etc.) (Marple et al., 1997; Good et al., 1983). Additionally, patients completed the SF-6, a six-item scale that measures functional status in six domains: general health, role function, physical function, social function, emotional health and physical pain (Ware, Nelson, Sherbourne \& Stewart, 1992). Patients were also evaluated for DSM-IV depressive and anxiety disorders with the PRIME-MD (Spitzer, Williams \& Kroenke,
1994). Patients who screened positive on the patient questionnaire portion of the PRIME-MD were interviewed with the Clinician Evaluation Guide to make criteria-based diagnoses of DSM-IV depressive and anxiety disorders.

\section{Immediate post-visit surveys}

Immediately after the visit, patients completed the MOS nine-item satisfaction survey (Rubin et al., 1993), which assesses overall satisfaction and eight domains of visit-specific satisfaction. In addition, patient questionnaires asked about residual serious illness worry as well as unmet expectations regarding a causal explanation, an estimate of symptom duration, a prescription, a diagnostic test, or a subspecialty referral (Marple et al., 1997). Patients were invited to write in any other unlisted unmet expectations. Patients completed the form in the waiting office, immediately after the visit. Using the computerized clinic database, prescription and diagnostic test orders were obtained for each patient as well as the total number of outpatient visits for 3 months before and after the index visit. Visit costs were tabulated using HCFA relative value units and converted to dollars using the 1996 Medicare schedule. Prescription costs were based on either HCFA rates or generics (when available).

\section{Two-week and three-month surveys}

Two weeks and three months after the visit, patients were mailed a questionnaire which included only the overall satisfaction question from the RAND-9 item instrument, due to concern about the patients' ability to recall answers on the eight visit-specific domains such as physician technical competence, compassion, office wait time, etc. Additional questions included symptom outcome and severity, residual serious illness worry, unmet expectations, functional status (MOS SF6), whether they had or anticipated having another physician visit for the original symptom and whether the symptom had lasted longer than they expected. After two mailed surveys, telephone contact of non-respondents was attempted.

\section{Physician variables}

Prior to study participation, physicians completed the Physician Belief Scale (PBS), a 32-item questionnaire that measures attitudes regarding psychosocial aspects of patient care (Ashworth, Williamson \& Montanco, 1984). Each question is followed by a five-point Likerttype response scale ranging from Disagree (1) to Agree (5). Scores range from 32 to 160 , with higher scores reflecting poorer psychosocial attitudes. This instrument has been found to be a reliable and valid measure of provider's psychosocial beliefs, and has also been correlated with the likelihood that physicians will 
experience encounters as difficult (Jackson \& Kroenke, 1999d) as well as with physician communication styles linked to satisfaction (Levinson, 1995).

After each patient visit, physicians completed the 10item Difficult Doctor-Patient Relationship Questionnaire (DDPRQ) (Hahn, Kroenke, Spitzer, Brody, Williams \& Linzer, 1996) to assess clinician-perceived difficulty of the encounter, and indicated whether a subspecialty referral was provided. The DDPRQ has been previously shown to be a reliable instrument with an internal consistency of $0.88-0.96$, with a score $>30$ indicating a 'difficult' encounter (Hahn, Thompson, Stern, Budner \& Wills, 1994).

\section{Analysis}

The primary analysis compared overall visit satisfaction at each of the three time points as a dichotomous response to the question: "Overall, how satisfied are you with the care you received for this problem?' ('Excellent' versus 'Very Good, Good, Fair, Poor'). Logistic regression models were created using overall satisfaction as the dependent variable. Each of the numerous potential independent predictors of satisfaction at each time-point were screened using analysis of variance, or the Kuskall-Wallis test as appropriate for continuous independent variables and maximum likelihood ratio Chi-square for categorical independent variables. The initial model included all variables significant at $p<0.25$ on univariate screen after the methods of Hosmer and Lemeshow (1989). Ninteen variables not significant on the univariate screen as an independent predictor of satisfaction, but which have been found in previous research to be associated with satisfaction were tested for potential confounding or interactive effects, (e.g., gender, functional status, PBS scores, and the presence of mental disorders). Because of concern about the importance of physician specific aspects of patient satisfaction, robust variance estimation, using the Huber correction for potential clustering by physicians was performed (Huber, 1967).

In order to assess the possibility of losing important information by this dichotomization, maximum-likelihood ordered logit models were also created. The variables deemed independent by logistic regression were found to be robust when satisfaction was modeled as an ordinal dependent variable.

This data was collected as part of a pre-post clinical trial of providing pre-visit information to clinicians on patient symptom-related expectations and mental disorders (Jackson \& Kroenke, 1999d). While there was no difference in satisfaction among the groups, there was a difference in unmet expectations post-visit. In our models, intervention status had neither an independent effect on satisfaction nor acted as a confounder on other variables in the model. Fitting our model within both intervention and control groups assessed the robustness of this finding. While confidence intervals were wider, as would be anticipated in smaller samples, there was no meaningful difference in our parameter estimates.

\section{Results}

Five hundred and twenty-eight adults were invited to participate and 500 agreed. Participants were similar to nonparticipants in terms of age, race, sex and type of symptom. Patients had a mean age of 54.7 years; half were women, and $49 \%$ were white and $45 \%$ AfricanAmerican. Ninety-four percent of patients were retired from military service, and they presented with a variety of symptoms, with more than one symptom present $15 \%$ of the time. The leading symptom category was musculoskeletal complaints, present in a third of subjects. Pain of some type was reported among 325 patients $(65 \%)$. Slightly more than half $(55 \%)$ had experienced their symptom less than 2 weeks and $68 \%$ less than 1 month.

Nearly all (98\%) patients had at least one pre-visit expectation including a desire for a causal explanation $(80 \%)$, anticipated time for recovery $(62 \%)$, medication prescription $(66 \%)$ diagnostic test $(56 \%)$ or subspecialty referral $(47 \%)$. Nearly two-thirds $(64 \%)$ were worried that their symptom might represent a serious illness.

A depressive or anxiety disorder was present in $29 \%$ of patients, with $11 \%$ experiencing two or more disorders, a frequency consistent with other reports of mental disorders in primary care settings (Kroenke, Jackson \& Chamberlin, 1997; Ormel, Von Korff, Uston, Pini, Korten \& Oldehinkel, 1994; Spitzer et al., 1994). Major depression was present in $8.4 \%$, other depressive disorders in $17.4 \%$, panic disorder in $1.4 \%$ and other anxiety disorders in $14.2 \%$ of patients.

Among 38 participating physicians, 35 were general internists and three were family practitioners. Twentytwo physicians were interns (first-year trainees) and 16 were staff physicians, though staff physicians saw the majority $(76 \%)$ of the study patients. One hundred and forty-eight of patient visits were with civilian contract physicians, who averaged 9.4 years of providing health care in this clinic. One hundred and twenty visits were with interns. The remaining 202 visits were with military physicians, averaging 6.8 years of service in this clinic. The mean age of participating clinicians was 35.6 years (median: 32.5 ), with staff physicians averaging 13 years of practice (range 4-25). Thirty-nine percent of clinicians were women, $11 \%$ were African-American, $5 \%$ Hispanic and 5\% Oriental. The PBS had a Cronbach's $\alpha$ of 0.91 . Seventy-six patient encounters $(15 \%)$ were rated as difficult by the provider. In our sample of 500 subjects, the internal consistency of the DDPRQ was 0.89 . 
Table 1

Fully satisfied vs. not fully satisfied

\begin{tabular}{|c|c|c|c|}
\hline Characteristic & $\begin{array}{l}\text { Fully } \\
\text { satisfied }\end{array}$ & $\begin{array}{l}\text { Not fully } \\
\text { satisfied }\end{array}$ & $p$ \\
\hline \multicolumn{4}{|l|}{ Age, (mean) } \\
\hline Immediately post visit & 58 & 51 & 0.0001 \\
\hline 2-week follow up & 56 & 54 & 0.23 \\
\hline 3-month follow up & 58 & 56 & 0.23 \\
\hline \multicolumn{4}{|l|}{ Female gender $(\%)$} \\
\hline Immediately post visit & 47 & 57 & 0.02 \\
\hline 2-week follow up & 52 & 52 & 0.97 \\
\hline 3-month follow up & 51 & 54 & 0.53 \\
\hline \multicolumn{4}{|c|}{ Mood or anxiety disorder $(\%)$} \\
\hline Immediately post visit & 27 & 32 & 0.25 \\
\hline 2-week follow up & 26 & 34 & 0.05 \\
\hline 3-month follow up & 24 & 33 & 0.04 \\
\hline \multicolumn{4}{|c|}{ Symptom duration at index visit (median) } \\
\hline Immediately post visit & 14 & 14 & 0.39 \\
\hline 2-week follow up & 12 & 28 & 0.0001 \\
\hline 3-month follow up & 14 & 28 & 0.0002 \\
\hline \multicolumn{4}{|c|}{ Number of symptoms endorsed (mean) } \\
\hline Immediately post visit & 3.8 & 4.2 & 0.12 \\
\hline 2-week follow up & 3.5 & 4.6 & $<0.0001$ \\
\hline 3-month follow up & 3.5 & 4.5 & 0.0009 \\
\hline \multicolumn{4}{|c|}{ Functional status score (mean) } \\
\hline Baseline & 22.7 & 21.3 & 0.003 \\
\hline 2-week follow up & 25.6 & 22.3 & $<0.0001$ \\
\hline Three week follow up & 21.4 & 18.4 & $<0.0001$ \\
\hline \multicolumn{4}{|c|}{ Recent stress (previous 2-weeks) at follow up (\%) } \\
\hline Immediately post visit & 37 & 47 & 0.02 \\
\hline 2-week follow up & 34 & 44 & 0.04 \\
\hline 3-month follow up & 26 & 48 & $<0.00001$ \\
\hline \multicolumn{4}{|c|}{ Pt reports receiving explanation of symptom cause during initial visit from doctor $(\%)$} \\
\hline Immediately post visit & 74 & 57 & $<0.00001$ \\
\hline 2-week follow up & 69 & 59 & 0.02 \\
\hline 3-month follow up & 71 & 57 & 0.005 \\
\hline \multicolumn{4}{|c|}{ Pt reports receiving explanation of likely symptom duration from doctor during initial visit $(\%)$} \\
\hline Immediately post visit & 48 & 31 & $<0.0001$ \\
\hline 2-week follow up & 42 & 35 & 0.11 \\
\hline 3-month follow up & 43 & 33 & 0.04 \\
\hline \multicolumn{4}{|c|}{ Unmet expectations (any) $(\%)$} \\
\hline Immediately post visit & 3 & 21 & $<0.0001$ \\
\hline 2-week follow up & 10 & 62 & $<0.0001$ \\
\hline 3-month follow up & 8 & 69 & $<0.0001$ \\
\hline \multicolumn{4}{|c|}{ Symptom outcome ( $\%$ improved $)$} \\
\hline 2-week follow up & 84 & 51 & $<0.00001$ \\
\hline 3-month follow up & 91 & 60 & $<0.00001$ \\
\hline \multicolumn{4}{|c|}{ Symptom severity on follow up, mean ( $0-10$ scale) } \\
\hline Immediately post visit & 5.4 & 5.8 & 0.04 \\
\hline 2-week follow up & 2.9 & 4.7 & $<0.00001$ \\
\hline 3-month follow up & 2.0 & 4.2 & $<0.00001$ \\
\hline \multicolumn{4}{|c|}{ Symptom lasted longer than expected $(\%)$} \\
\hline 2-week follow up & 53 & 78 & $<0.0001$ \\
\hline 3-month follow up & 45 & 80 & $<0.0001$ \\
\hline \multicolumn{4}{|c|}{ Have had a $\mathrm{f} / \mathrm{u}$ visit for this problem $(\%)$} \\
\hline 2-week follow up & 28 & 48 & $<0.0001$ \\
\hline 3-month follow up & 42 & 52 & 0.06 \\
\hline
\end{tabular}


Table 1 (continued)

\begin{tabular}{|c|c|c|c|}
\hline Characteristic & $\begin{array}{l}\text { Fully } \\
\text { satisfied }\end{array}$ & $\begin{array}{l}\text { Not fully } \\
\text { satisfied }\end{array}$ & $p$ \\
\hline \multicolumn{4}{|c|}{ Anticipate needing another visit for this problem $(\%)$} \\
\hline Immediate post visit & 55 & 67 & 0.006 \\
\hline 2-week follow up & 51 & 80 & $<0.0001$ \\
\hline 3-month follow up & 41 & 77 & $<0.0001$ \\
\hline \multicolumn{4}{|c|}{ Serious illness worry at follow up $(\%)$} \\
\hline Immediately post visit & 30 & 34 & 0.37 \\
\hline 2-week follow up & 28 & 52 & $<0.00001$ \\
\hline 3-month follow up & 16 & 50 & $<0.00001$ \\
\hline \multicolumn{4}{|c|}{ Physician belief score (mean) } \\
\hline Immediately post visit & 67.8 & 68.6 & 0.43 \\
\hline 2-week follow up & 68.3 & 68.7 & 0.78 \\
\hline 3-month follow up & 68.3 & 67.9 & 0.74 \\
\hline \multicolumn{4}{|c|}{ Patient considered 'difficult' by physician $(\%)$} \\
\hline Immediately post visit & 12 & 19 & 0.03 \\
\hline 2-week follow up & 12 & 21 & 0.01 \\
\hline 3-month follow up & 13 & 15 & 0.76 \\
\hline
\end{tabular}

\section{Satisfaction}

Two hundred and sixty patients $(52 \%)$ rated their overall care as 'excellent' immediately after the visit, increasing to $59 \%$ at 2 weeks and $63 \%$ by 3 months. Immediately after the visit, $18 \%$ of patients rated their encounter as only 'good, fair or poor,' falling to $13 \%$ and $14 \%$ by 2 weeks and 3 months, respectively. There was a high correlation between overall satisfaction and patient responses to each of the eight specific domains of satisfaction with correlation coefficients ranging from 0.62 to 0.93 . Table 1 compares characteristics of patients in the two groups: fully satisfied (i.e., rated their overall care as excellent) versus not fully satisfied (i.e., rated their overall care as less than excellent).

\section{Immediate post-visit satisfaction}

On univariate analysis, older patients and those who received an explanation of the symptom's cause or anticipated time for resolution were more likely to be fully satisfied, while having unmet expectations, more severe symptoms, worse functional status or being considered 'difficult' by the physician decreased satisfaction (Table 1). Satisfaction was not associated with symptom duration, specific type of pre-visit expectations, presence of mental disorders, number of other somatic symptoms, utilization, or other physician characteristics (resident versus staff, number of years of practice, or PBS scores). There was no interaction between physician and patient demographic variables. There was also no difference in satisfaction rates between patients with specific categories of mental disorders (major or minor depression, panic or general- ized anxiety disorder) or with greater number of comorbid mental disorders.

Multivariate analysis of immediate post-visit satisfaction found that having no residual unmet expectations, receiving an explanation of symptom cause and likely duration, having better functional status, and being older than 65 years of age independently predicted an increased likelihood of being fully satisfied (Table 2). When all the domains of satisfaction were summed, this combination of variables explained $26 \%$ of the variance within a linear regression model.

\section{Two-week and three-month satisfaction}

Follow-up surveys were available in 465 (93\%) of patients at 2 weeks and $415(83 \%)$ at 3 months. Patients with shorter symptom duration at the index visit were more likely to be fully satisfied at 2 weeks and 3 months, while the presence of a mood or anxiety disorder or greater number of other somatic symptoms decreased follow-up satisfaction (Table 1). Variables that were associated with satisfaction at 2 weeks and 3 months included: reporting no unmet expectations of care; experiencing symptom improvement or less symptom severity; less serious illness worry; feeling that the symptom had not lasted longer than expected and not requiring another physician visit for the symptom. Patients considered 'difficult' by the clinician were more likely to be dissatisfied at 2 weeks, but not 3 months. Functional status improved between the index visit and 2-week follow-up. The further, smaller increase in functioning between 2 weeks and 3 months was not significantly different. Better functional status scores were associated with greater satisfaction (Table 1). 
Table 2

Independent, multivariate predictors of satisfaction

\begin{tabular}{|c|c|c|c|}
\hline Characteristic & Immediately post-visit $^{\mathrm{a}}$ & 2 weeks $^{\mathrm{b}}$ & 3 months $^{\mathrm{c}}$ \\
\hline No unmet expectations & $7.0(3.4-14.2)$ & $15.0(8.6-26.3)$ & $21.1(12.8-34.7)$ \\
\hline Received an explanation of how long symptom is likely to last & $1.8(1.1-2.8)$ & NS & NS \\
\hline Received an explanation of symptom etiology & $1.7(1.1-2.4)$ & NS & NS \\
\hline Age $>65$ & $2.7(1.3-2.9)$ & $1.9(1.2-3.1)$ & $1.9(1.1-3.5)$ \\
\hline Functional status (summative score) & $1.05(1.02-1.09)$ & $1.1(1.05-1.2)$ & $1.1(1.01-1.2)$ \\
\hline Symptom 'better or gone' & NA & $3.0(1.8-5.1)$ & $2.7(1.1-6.5)$ \\
\hline Neither requiring nor anticipating another doctor visit for the symptom & NA & $2.02(1.2-3.4)$ & $2.9(1.9-4.7)$ \\
\hline
\end{tabular}

${ }^{\mathrm{a}}$ Immediately post-visit: Hosmer and Lemeshow $\chi^{2}(\mathrm{df}=-8)=6.79, p=0.82$, area under ROC: 0.70 .

${ }^{\mathrm{b}}$ 2-week: Hosmer and Lemeshow $\chi^{2}(\mathrm{df}=8)=6.72, p=0.56$ area under ROC: 0.86 .

c 3-month: Hosmer and Lemeshow $\chi^{2}(\mathrm{df}=8)=2.23, p=0.97$, area under ROC: 0.89 .

Multivariate modeling of satisfaction at 2 weeks and 3 months produced identical covariate patterns (Table 2). Independent correlates of satisfaction at both time points included symptom improvement, reporting no residual expectations, neither requiring nor anticipating a need for another doctor visit for the symptom, and better functioning. Linear regression revealed that $38 \%$ and $40 \%$ of the variance in satisfaction at 2 weeks and 3 months, respectively, were explained by this combination of variables.

\section{Discussion}

Among patients presenting to a walk-in clinic with physical symptoms, $52 \%$ were fully satisfied with the care they had received immediately after the visit, increasing to $59 \%$ at 2 weeks and $63 \%$ by 3 months. Older patients were more likely to be fully satisfied, but other demographic characteristics had no effect at any time point. Neither the type, duration nor severity of symptom or the type or number of pre-visit expectations or the amount of money spent during the index visit correlated with satisfaction.

Mood and anxiety disorders were weakly associated with dissatisfaction at 2 weeks and 3 months, though not at baseline. This association faded when examined with multivariate techniques, controlling for other components of satisfaction. This lack of effect by psychiatric status was also seen when examined by the specific type or number of comorbid mood and anxiety disorders. While this finding contradicts previous reports of a relationship between dissatisfaction and mental disorders, there are a number of possible reasons for this discrepancy. Our study included more patient-specific variables that allowed greater control for other potentially more powerful covariates of satisfaction. We measured visit-specific satisfaction, rather than overall satisfaction with care during the previous year, as used by most studies (Greenley et al., 1982; Linn \& Green- field, 1982; Herman et al., 1998). Our data suggests that satisfaction, measured outside the context of an immediately completed patient visit needs to take into account functional and symptom-specific improvement. Each of these three studies (Greenley et al., 1982; Linn \& Greenfield, 1982; Herman et al., 1998) found a stronger relationship between functional and symptom-specific indices and satisfaction than with mental disorders. Linn \& Greenfield (1982) used the Zung depression index, Greenley, a 10-item subgroup of the Langner index; neither made specific DSM IV diagnoses. Hueston et al. (1996) examined patients with personality disorders rather than the mood or anxiety disorders that are more common in primary care. Another involved Swedish primary care patients a cohort that may not be generalizable to US encounters (Hansson et al., 1994). Hermann linked Medicare claims data with Medicare satisfaction surveys; diagnosis were based on billing by their clinicians. Since as few as $10 \%$ of mental disorders in primary care are identified (Ormel, Koeter, van dn Brink \& van de Willig, 1991; Spitzer et al., 1994; Sartorious, Goldberg, de Girolamo, Costa e Silva, Lecrubier \& Wittchen, 1990), this may represent a more severe spectrum of mental disease burden than among our cohort. Our cohort is likely a better representation of the spectrum of mental disorders seen in primary care and may more clearly elucidate their relationship with visit-specific satisfaction.

In our study, functional status had an independent effect on satisfaction at all time-points measured. This is consistent with previous studies finding that patients with greater functional impairment are less likely to be satisfied with the care they receive (Cleary \& McNeil, 1988; Cleary et al., 1991; Hermann et al., 1998; Williams \& Calnan, 1991).

Unmet expectations emerged as the strongest independent correlate with satisfaction, although no specific residual expectation was identified as being more important than another. Others have also found an association between unmet expectations and satisfaction 
(Marple et al., 1997), though ours is the first to analyze its contribution in relation to other satisfaction components. Whether unmet expectations are a cause or simply a marker of dissatisfaction is unclear. Two studies that included an intervention to improve how physicians handle patient expectations both produced significant decreases in the number of unmet expectations without significantly affecting satisfaction. (Joos, Hickam, Gordon \& Baker, 1996; Jackson et al., 1999a) Even with the large number of patient-specific variables, we were able to account for less than half the variance in satisfaction. Patients may report greater unmet expectations because they are dissatisfied, rather than vice versa.

Immediately after the visit, satisfaction was most strongly related to measures of doctor-patient communication, including a lack of unmet expectations and receiving an explanation of the symptom's cause and an estimate of likely symptom duration. By 2 weeks and 3 months, however, satisfaction was related to the course and impact of the patient's underlying symptom. Patients who failed to improve were less likely to be satisfied, as were those who had to be seen again for their symptoms or anticipated such a need, or who had worse functional status. In our study, as in previous ones (Kane et al., 1997), patient satisfaction correlated with absolute levels of impairment rather than with the amount of change in symptom severity or functional status. If satisfaction with a visit for a physical symptom is measured at any time point other than immediately after the visit, then satisfaction may be a proxy for symptom or functional improvement rather than satisfaction with intrinsic characteristics of the physician.

The importance of symptom outcome on satisfaction at 2 weeks and 3 months is reflected by the fact that patients who were fully satisfied immediately after the visit, but did not experience symptom improvement at 2 weeks or 3 months, were less likely to be satisfied than patients who improved (2-week: OR: $0.20,95 \% \mathrm{CI}$ : 0.10-0.4; 3-month: OR: 0.09 , 95\% CI: $0.04-0.21$ ). Conversely, patients initially less than fully satisfied immediately after their visit, but with symptom improvement were highly satisfied on follow up, compared with patients initially satisfied but without symptom improvement (2-week: OR: 5.3, 95\% CI: 2.6-11.0; 3month: $3.1,95 \%$ CI: 1.4-6.9). The lack of relationship between immediate post-visit satisfaction and satisfaction at 2 weeks and 3 months is reflected by the low correlations between immediate and follow up satisfaction (2-week Spearman's rho: 0.32, 3-month Spearman's rho $=-0.23$, both $p<0.00001)$.

The temporally varying components of patient satisfaction suggest that attention should be paid to the time frame during which questions about satisfaction are asked. For patients presenting with physical symptoms, asking about satisfaction at different time points may yield different outcomes and may be measuring different domains. If the desire is to measure satisfaction with specific physician behavior, then the question may need to be asked immediately after the visit. This may explain the negative results in a recent study of intervening on physician behavior, but that measured satisfaction at a later time point (Brown, Boles, Mullooly \& Levinson, 1999). Satisfaction measured outside the context of an immediate visit may be a proxy for symptom or functional status improvement rather than a measure of satisfaction. After the patient leaves the office, and certainly by two weeks, much of the variance in visit-specific satisfaction is directly or indirectly related to improvement in symptoms or functioning rather than physician characteristics, as suggested by Jutalis et al. (1997). While it could be argued that patients are in a better position to determine whether or not they are satisfied at a later time-point, after they have had the opportunity to decide whether the physicians' advice is 'right,' satisfaction at that time point is really measuring satisfaction with the patient's health outcome, rather than satisfaction with the individual physician. Previous studies have raised concerns about using satisfaction as a surrogate marker for the technical quality of the care they receive. Patients have been found to be very uncritical, allowing care to be of extremely poor quality before expressing dissatisfaction (Kurata, Nogava, Philips, Hoffman \& Werblun, 1992; Williams, 1994) Very few studies have assessed how well satisfaction correlates with quality of care (Cleary et al., 1991). One study in which technical aspects of eye care were objectively rated and compared to the patient's perception of quality revealed that patients were poor at assessing technical quality (Haas-Wilson, 1994). Other studies have found that patients' satisfaction with care is higher when tests are obtained, even when the tests are of no diagnostic value (Sox, Margulies \& Sox, 1981). While most patients presenting with a physical symptom improve (Kroenke \& Jackson, 1998), the specific physician behaviors that foster such improvement remain unknown. At the least, this data suggests a need to risk-adjust for patient health status in comparing physicians on patient satisfaction, as well as to be aware of when the question is asked.

Our study suggests two separate models for patient satisfaction at different time-points:

- Immediate post-visit satisfaction $=$ Demographics (age) + Patient expectations + Patient functioning + Patient-doctor interaction (receiving an explanation of symptom cause and likely duration).

- 2-week/3-month satisfaction $=$ Demographics (age) + Patient expectations + Patient functioning + Symptom improvement.

The immediate post-visit model explained $26 \%$ of the variance in satisfaction, while the 2-week and 3-month 
models explained $38 \%$ and $40 \%$, respectively. Although this is considerably higher than most studies, it still demonstrates important gaps in our understanding of which factors impact upon patient satisfaction. Qualitative approaches to assessing interpersonal aspects of the patient-doctor relationship, such as audiotape or videotape coding of actual encounters, may be necessary to tease out provider communication skills, affective aspects of the interaction, nonverbal behaviors, or other components which cannot be captured by surveys. Critical incident interviews of patients who express dissatisfaction or unmet expectations after an encounter may also be informative.

Our study has several limitations. First, because the sample consisted of symptomatic walk-in patients seeing new physicians, one should be cautious in generalizing these findings to established clinician-patient relationships or visits not centered on a physical complaint. The walk-in clinic setting was a purposive selection, because patients seen in continuity settings typically report being fully satisfied greater than $90 \%$ of the time. We hypothesized that there would be greater levels of dissatisfaction in such a setting and that it might be easier to isolate important variables that made up satisfaction in the absence of more difficult satisfaction variables based on numerous previous patient-physician interactions. Even in continuity settings, physical symptoms are common, accounting for over half of all outpatient visits; an estimated 400 million US clinic encounters each year (Schappert, 1992).

Second, the sample was drawn from a military clinic, which may make some worry about generalizing our results to civilian care. This clinic, however, is part of Walter Reed Army Medical Center, best described as a tertiary health care system. Ninety-four percent of the patients participating in this study were retired from military service. One-third of the sample was seen by civilian contractors; averaging almost a decade of service in this clinic, another third by interns, with the 2-3 year turnover typical of all resident training programs, the final third by active duty physicians, averaging 6.8 years of seeing patients in this clinic. During this study period there were no deployments or tasking from the clinic to support military operations. Previous studies have demonstrated that patients seen in military tertiary care facilities very closely resemble civilian patients, with the same distribution of medical problems, functional status limitations, presence of mental disorders, satisfaction levels and types of outpatient procedures performed (Jackson et al., 1999b; Jackson, O’Malley \& Kroenke, 1999c).

Third, we used a brief checklist to detect symptomrelated expectations. Some investigators using much longer instruments or interviews have identified other common expectations (e.g., physician preparation for the visit, history taking; physical examination) that we did not measure. (Good, 1984; Kravitz et al., 1996; Uhlmann et al., 1984a, 1984b) Although we invited patients to write in other expectations, they did so infrequently.

Fourth, we included no direct observation of doctorpatient encounters. Our aim was to capture patients in real time and to minimize, as much as possible any Hawthorne effect. While 2-week and 3-month satisfaction was linked to symptom outcome, immediate postvisit satisfaction was heavily influenced by variables reflecting doctor-patient communication, specifically explaining to the patient the symptom's cause and how long it was likely to last. In contrast, our surrogate and generic marker of physician communication skills, the PBS, did not correlate with satisfaction. This differs from one previous study which found PBS scores correlated with better physician communication skills and with a higher portion of time spent discussing psychosocial issues, which in turn has been found to correlate with greater satisfaction (Levinson, 1995). However, a recent study of depression found a poor correlation between PBS scores and provider communication skills (Badger et al., 1994). Intervention trials attempting to improve physician communication regarding patient expectations may need to audiotape encounters, explicitly ask patients about unmet expectations, or employ other direct measures rather than the PBS or other generic instruments.

Fifth, we used a very brief measurement of functional status, the MOS SF-6, a measure that is not yet fully accepted in the measurement community. The MOS SF6 was designed to be an ultra-short measure of functional status, particularly useful in studies, such as ours, in which a large number of questions are asked. Each question was selected from the longer SF-36 to represent one of six domains. Each question has been found to have good correlation with the score in that domain from the SF-36, and is better assessment of functional status based only on a single question (Ware et al., 1992). Ware concluded that the SF-6 is adequate for group evaluations, but may not be sufficiently reliable for individual comparisons. While patients reporting worse functioning in all six domains were found to be less satisfied at both 2 weeks and 3 months, we chose to report on only an overall functioning score, from concern about the validity and reliability of assessing each domain on the basis of only one question. In our study, the six questions on the SF6 had reasonable reliability, with a Cronbach's $\alpha$ of 0.77 . Consistent with studies using longer measures of functional status, patients in our data set with mental disorders (Spitzer et al., 1994), and patients considered difficult (Hahn et al., 1996), had worse functioning. In addition, patients experiencing symptom improvement had improvement in functional status scores while those not reporting improvement did not, with a linear relationship between overall functional status score and symptom severity at each of the time-points. 
A final limitation is that our study did not include a separate assessment of the quality of care provided; one of the goals of measuring satisfaction is to indirectly assess quality of care. Some researchers argue that satisfaction is itself an outcome, worthy of measure in its own right. (Donabedian, 1968; Jackson \& Kroenke, 1997) It seems clear that satisfaction is not a good surrogate marker for technical care quality (HaasWilson, 1994; Kurata et al., 1992; Williams \& Calnan, 1994), and few studies have assessed how well satisfaction correlates with quality of care (Cleary et al., 1991). A meta-analysis found that very few satisfaction surveys asked patients to make judgments regarding the technical quality of care (Wensing, Grol \& Smits, 1994).

The strengths of our study include its prospective design, large sample size, use of a valid, reliable instrument to make mental diagnoses (Mulrow, Williams \& Gerety, 1995), measurement of multiple symptom-relevant outcomes at different time points in the patients' care and high response rates. The method of assigning walk-in patients in an unselected fashion to physicians staffing a particular clinic session prevented biased sampling from potential concentration of patients with known psychosocial problems into particular clinician's practices.

As continued emphasis is placed on patient-centered medicine and on the patient-physician relationship (Glass, 1996; Laine, 1996), patient satisfaction will continue to be an important outcome measure. A health system that does not satisfy its consumers, regardless of technical quality, does not optimally serve society (Donabedian, 1966). Our study suggests that immediately after the visit, patient satisfaction is strongly influenced by patient-doctor communication variables; while by 2-weeks outcome of the patients' presenting symptom has an increasingly greater effect. At all time points, satisfaction is influenced by both patient age and functional status. If providers are to be judged on the basis of patient satisfaction, adjustments need to be made for the timing of the assessment as well as certain patient characteristics.

\section{Acknowledgements}

This project was funded by Uniformed Services University of the Health Sciences (Intramural Grant no. 32001).

\section{References}

Ashworth, C. D., Williason, P., \& Montanco, D. (1984). A scale to measure physician beliefs about psychosocial aspects of patient care. Soc. Sci. Med., 19, 1235-1238.
Badger, L. W., deGruy, F. V., Hartman, J., Plant, M. A., Leeper, J., Ficken, R., Maxwell, A., Rand, E., Anderson, R., \& Templeton, B. (1994). Psychosocial interest, medical interviews, and the recognition of depression. Arch. Fam. Med., 3, 899-907.

Brody, D. S., Miller, S. M., Lerman, C. E., Smith, D., Lazaro, C., \& Blum, M. (1989). The relationship between patients' satisfaction with their physicians and perceptions about interventions they desired and received. Med. Care, 27, 1027-1035.

Brown, J. B., Boles, M., Mullooly, J. P., \& Levinson, W. (1999). Effect of clinician communication skills training on patient satisfaction. Arandomized, controlled trial. Ann. Intern. Med., 131(11), 822-829.

Burgoyne, R. W., Staples, F. R., Yamamoto, J., Wolkon, G. H., \& Kline, F. (1979). Patients requests of an outpatient clinic. Arch. Gen. Psych., 36, 400-403.

Cleary, P. D., \& McNeil, B. J. (1988). Patient satisfaction as an indicator of quality care. Inquiry, 25, 25-36.

Cleary, P. D., Edgman-Levitan, S., Robertts, M., Moloney, T. W., McMullen, W., Walker, J. D., \& Delbanco, T. L. (1991). Patients evaluate their hospital care: a national survey. Health Aff. (Winter), 10, 254-267.

Covinsky, K. E., Rosenthal, G. E., Chren, M. M., Justice, A. C., Fortinsky, R. H., Palmer, R. M., \& Landefeld, S. (1988). The relation between health status changes and patient satisfaction in older hospitalized medical patients. J. Gen. Intern. Med., 13, 223-229.

Donabedian, A. (1966). Evaluating the quality of medical care. Milbank Mem. Fund. Q., 44, 166-206.

Glass, R. M. (1996). The patient-physician relationship. JAMA focuses on the center of medicine. JAMA 275, 147-148

Good, M. D., Good, B. J., \& Nassi, A. J. (1983). Patient requests in primary health care settings: development and validation of a research instrument. J. Behav. Med., 6, 151-169.

Greene, J. Y., Weinberger, M., \& Mamlin, J. J. (1980). Patient attitudes toward health care: expectations of primary care in a clinic setting. Soc. Sci. Med., 14, 133-138.

Greenley, J. R., Young, T. B., \& Schoenherr, R. A. (1982). Psychological distress and patient satisfaction. Med. Care, 20, 373-385.

Haas-Wilson, D. (1994). The relationships between the dimensions of health care quality and price: the case of eye care. Med. Care, 32, 175-182.

Hahn, S. R., Thompson, K. S., Stern, V., Budner, N. S., \& Wills, T. A. (1994). The difficult doctor-patient relationship: somatization, personality and psychopathology. J. Clin. Epidemiol., 47, 647-658.

Hahn, S. R., Kroenke, K., Spitzer, R. L., Brody, D., Williams, J. B., \& Linzer, M., et al. (1996). The difficult patient: prevalence, psychopathology and functional impairment. $J$. Gen. Intern. Med., 11, 1-8.

Hall, J. A., \& Dornan, M. C. (1990). Patient sociodemographic characteristics as predictors of satisfaction with medical care. Soc. Sci. Med., 6, 811-818.

Hansson, L., Borgquist, L., Nettelbladt, P., \& Nordstrom, G. (1994). The course of psychiatric illness in primary care patients. A 1-year's follow-up. Soc. Psychiatry Psychiatri. Epidemiol., 29, 1-7.

Henley, B., \& Davis, M. S. (1967). Satisfaction and dissatisfaction: a study of the chronically ill aged patients. J. Hlth. Soc. Behav., 8, 65-84. 
Hermann, R. C., Ettner, S. L., \& Dorwart, R. A. (1998). The influence of psychiatric disorders on patients ratings of satisfaction with health care. Med. Care, 36, 720-727.

Hosmer, D. W., \& Lemeshow, S. (1989). Applied logistic regression. New York: Wiley.

Huber, P. J. (1967). The behavior of maximum likelihood estimates under non-standard condition. In Proceedings of the Fifth Berkeley Symposium on Mathematical Statistics and Probability, vol. 1 (pp. 221-233). Berkeley, CA: University of California Press.

Hueston, W. J., Mainous, A. G., \& Schilling, R. (1996). Patients with personality disorders: functional status, health care utilization and satisfaction with care. J. Fam. Practice, $42,54-60$.

Jackson, J. L., \& Kroenke, K. (1997). Patient satisfaction and quality of care. Military Medicine, 162, 273-277.

Jackson, J. L., Kroenke, K., \& Chamberlin, J. (1999a). A clinical trial to assess the effect of physician knowledge of patient serious illness worry, expectations and psychiatric disorders. Arch. Fam. Practice, 8(2), 135-142.

Jackson, J. L., Strong, J., Cheng, E. Y., \& Meyer, G. S. (1999b). Patients, diagnosis and procedures in a military internal medicine clinic, comparison with civilian practices. Military Medicine, 164(3), 194-197.

Jackson, J. L., O’Malley, P. G., \& Kroenke, K. (1999c). A Psychometric comparison of military and civilian medical practices. Military Medicine, 164(2), 112-115.

Jackson, J. L., \& Kroenke, K. (1999). The difficult patient: clinical predictors and outcomes. Arch. Internal Medicine, 159, 1069-1075.

Jackson, J.L., Cheng, E.Y., Jones, D.L., \& Meyer, G. (1999). Comparison of discharge diagnoses and inpatient procedures between Military and Civilian health care systems. Military Medicine, 164(10), 701-704.

Jatulis, D. E., Bundek, N. I., \& Legorreta, A. P. (1997). Identifying predictors of satisfaction with access to medical care and quality of care. Am. J. Med. Qual., 12, 11-18.

Johnson, J. E., Pinholt, E. M., Jenkins, T. R., \& Carpenter, J. L. (1988). Content of internal medicine practice in an academic Army Medical Center and an Army Community Hospital. Military Medicine, 153, 21-25.

Jones, R. B., Carnon, A. G., Wylie, H., \& Hedley, A. J. (1993). How do we measure consumer opinions of outpatient clinics. Pub. Hlth., 107, 235-241.

Joos, S. K., Hickam, D. H., Gordon, G. H., \& Baker, L. H. (1996). Effects of a physician communication intervention on patient care outcomes. J. Gen. Intern. Med., 12, 597-606.

Kane, R. L., Maciejewski, M., \& Finch, M. (1997). The relationship of patient satisfaction with care and clinical outcomes. Med. Care, 35, 714-730.

Korsch, B. M., Gozzi, E. K., \& Francis, V. (1968). Gaps in doctor-patient communication. Part 1. Doctor-patient interaction and patient satisfaction. Peds., 42, 855-871.

Kravitz, R. L., Cope, D. W., Bhrany, V., \& Leake, B. (1994). Internal medicine patients' expectations for care during office visits. J. Gen. Intern. Med., 9, 75-81.

Kravitz, R. L., Callahan, E. J., Paterniti, D., Antoneius, D., Dunham, M., \& Lewis, C. E. (1996). Prevalence and sources of patients' unmet expectations for care. Ann. Intern. Med., $125,730-737$.
Kroenke, K., Jackson, J. L., \& Chamberlin, J. (1997). Depressive and anxiety disorders in patients presenting with physical complaints. Am. J. Med., 103, 339-347.

Kroenke, K., \& Jackson, J. L. (1998). Outcome in general medical patients presenting with common symptoms: a prospective study with a 2 -week and a 3-month follow-up. Fam. Prac., 15(5), 398-403.

Kurata, J. H., Nogawa, A. N., Philips, D. M., Hoffman, S., \& Werblun, M. N. (1992). Patient and provider satisfaction with medical care. J. Fam. Prac., 35, 176-179.

Laine, C. (1996). Patient-centered medicine. A professional evolution. JAMA, 275, 152-156.

Larsen, D. E., \& Rootman, I. (1976). Physician role performance and patient satisfaction. Soc. Sci. Med., 10, 29-32.

Lazare, A., \& Eisenthal, S. (1977). Patient requests in a walk-in clinic. J. Nerv. Ment. Dis., 165, 330-340.

Levinson, W. (1995). Physician's psychosocial beliefs correlate with their communication skills. J. Gen. Intern. Med., 10, 375-379.

Like, R., \& Zyzanski, S. J. (1987). Patient satisfaction with the clinical encounter: social psychological determinants. Soc. Sci. Med., 24, 351-357.

Linder-Pelz, S. U. (1982a). Toward a theory of patient satisfaction. Soc. Sci. Med., 16, 577-582.

Linder-Pelz, S. U. (1982b). Social psychological determinants of patient satisfaction: a test of five hypotheses. Soc. Sci. Med., 16, 583-589.

Linn, L. S., \& Greenfield, S. (1982). Patient suffering and patient satisfaction among the chronically ill. Med. Care, 20, 425-431.

Locker, D., \& Dunt, D. (1978). Theoretical and methodological issues in sociological studies of consumer satisfaction with medical care. Soc. Sci. Med., 12, 283-292.

Marple, R., Lucey, C., Kroenke, K., Wilder, J., \& Lucas, C. (1997). A prospective study of concerns and expectations in patients presenting with common symptoms. Arch. Intern. Med., 157, 1482-1488.

Mulrow, C. D., Williams, J. W., \& Gerety, M. B., et al. (1995). Case-finding instruments for depression in primary care settings. Ann. Int. Med., 122, 913-921.

Ormel, J., Koeter, M. W. J., van dn Brink, W., \& van de Willig, G. (1991). Recognition, management, and course of anxiety and depression in general practice. Arch. Gen. Psychiatry, 48, 700-706.

Ormel, J., Von Korff, M., Uston, T. B., Pini, S., Korten, A., \& Oldehinkel, T. (1994). Common mental disorders and disability across cultures: results from the WHO collaborative study on psychological problems in general health care. JAMA, 272, 1741-1748.

Roter, D. L., Stewart, M., Putnam, S. M., Lipkin Jr., M., Stiles, W., \& Inui, T. S. (1997). Communication patterns of primary care physicians. JAMA, 277, 350-356.

Rubin, H. R., Gandek, B., Rogers, W. H., Kosinski, M., McHorney, C. A., \& Ware, J. E. (1993). Patients ratings of outpatient visits in differ practice settings. Results of the medical outcomes study. JAMA, 270, 835-840.

Sanchez-Menegay, C., \& Stalder, H. (1994). Do physicians take into account patients' expectations?. J. Gen. Int. Med., 9, 404-406.

Sartorius, N., Goldberg, D., de Girolamo, G., Costa e Silva, J. A., Lecrubier, Y., \& Wittchen, H. U. (1990). Psychological 
disorders in general medical settings. Lewiston, NY: Hofgrebe \& Huber.

Schappert, S. M. (1992). National ambulatory medical care survey: 1989 summary. National center for health statistics. Vital Hlth. Stat., 13(110), 1-17.

Sox Jr., H. C., Margulies, I., \& Sox, C. H. (1981). Psychologically mediated effects of diagnostic tests. Ann. Int. Med., 95, 680-685.

Spitzer, R. L., Williams, J. B. W., \& Kroenke, K., et al. (1994). Utility of a new procedure for diagnosing mental disorders in primary care: the PRIME-MD 1000 study. JAMA, 272, $1749-1756$.

Temkin-Greener, H., \& Winchell, M. (1991). Medicaid beneficiaries under managed care: provider choice and satisfaction. Hlth. Serv. Res., 26, 509-529.

Uhlmann, R. F., Carter, W. D., \& Inui, T. S. (1984a). Fulfillment of patient requests in a general medicine clinic. Amer. J. Pub. Hlth., 74, 257-258.

Uhlmann, R. F., Inui, T. S., \& Carter, W. B. (1984b). Patient requests and expectations. Definitions and clinical applications. Med. Care, 22, 681-685.

Ware, J. E., Nelson, E. C., Sherbourne, C. D., \& Stewart, A. L. (1992). Preliminary tests of a six-item general health survey: a patient application in measuring functioning and well being. In J. E. Ware, \& E. L. Stewart (Eds.), The medical outcomes study approach (pp. 291-308). Durham, NC: Duke University Press.

Wensing, M., Grol, R., \& Smits, A. (1994). Quality judgements by patients on general practice care: a literature analysis. Soc. Sci. Med., 38, 45-53.

Weiss, B. D., \& Senf, J. H. (1990). Patient satisfaction survey instrument for use in health maintenance organizations. Med. Care, 28, 434-445.

Williams, S. J., \& Calnan, M. (1991). Convergence and divergence: assessing criteria of consumer satisfaction across general practice, dental and hospital care settings. Soc. Sci. Med., 33, 707-716.

Williams, B. (1994). Patient satisfaction: a valid concept. Soc. Sci. Med., 38, 509-516.

Wyshak, G., \& Barsky, A. (1995). Satisfaction with and effectiveness of medical care in relation to anxiety and depression. Patient and physicain ratings compared. Gen. Hosp. Psychiatry, 17, 108-114.

Zastowny, T. R., Roghman, K. J., \& Hengst, A. (1983). Satisfaction with medical care: replications and theoretic reevaluation. Med. Care, 21, 294-322. 